\title{
A Bridge too Far or a Bridge to the Future? A case study in online assessment at Charles Sturt University
}

\author{
Janet F. Buchan and Michael Swann \\ Charles Sturt University
}

The in house development of an online assessment tool, OASIS, has provided a unique opportunity to research the use of online assessment in teaching and learning across the university. The developing relationship between IT staff, educational designers and academics serves as a model for integrated and evolving management systems which demonstrate how academic research is informing improvements in applying educational technology. A framework, the Bridge Support Framework for Online Learning, is proposed for the support and implementation of online learning systems. A case study in online assessment in a microeconomics subject describes the development of this framework in response to a 'systems' failure when using the online assessment software tool during a major assessment event for a large external student cohort. As the university moves towards an open source learning management system for 2008, the range of online assessment methods will increase. It is here that our case study and the proposed Bridge Support Framework have potential value in learning from history to improve processes and procedures for the future.

\section{Introduction}

At Charles Sturt University (CSU) the nature of in house software development and cross-divisional support of online technologies has given the authors a unique opportunity to contribute to the evolution of the online assessment software itself, to play an integral role in the development of associated support processes and, through research, to gain an understanding of exactly how online multiple choice assessment is being used in teaching and learning throughout the university. A study supported by a CSU Scholarship in Teaching Fund grant is enabling the researchers to investigate more deeply the effectiveness of this form of assessment in enhancing learning and teaching. 
To date CSU has had a limited number of mainstream online assessment tools available to staff and students. These include online forums (discussion boards) for collaborative discussion; online submission of assignments (through the CSU developed Electronic Assessment Submission Tracking System, EASTS) and online marking. On a smaller scale, individual disciplines and subjects use a variety of online (or e-learning) technologies such as interactive CDs and online courses to achieve specific learning outcomes such as collaborative learning, critical reflection and problem solving (Donnan, 2006; Sivapalan \& Cregan, 2005; Kerka \& Wonnacott, 2000). This discussion will confine its focus to certain aspects of our recent experience with online multiple choice assessment. As our university moves rapidly towards the implementation of an open source learning management system (LMS) in 2008, this range of online assessment methods will increase with the introduction of new tools such as wikis, blogs, gradebooks and more integrated interactivity. Along with this increase in availability of assessment tools (amongst other enhanced features) comes the increased responsibility for supporting the implementation and ongoing development of a university wide, open source learning management system (Wheeler, 2007). It is here that our case study and the proposed Bridge Support Framework have potential value, learning from experience to improve processes and procedures for the future.

\section{The evolution of online assessment at CSU}

CSU introduced online multiple choice assessment in 1998 with a pilot trial of an in house developed, online multiple choice assessment quiz/test tool, OASIS (Online Assessment Submission Information System). Since then, this mode of assessment has been used successfully by staff and students (see later) to enhance learning through a variety of largely formative tasks, i.e. done for feedback rather than marks, and some summative assessment tasks, i.e done for both feedback and marks (Nichols, 2003) since its initial introduction as a pilot trial in 1998 (Buchan \& Pitcher, 2005). Following substantial technical upgrades to the software in 2003 and 2005, increased support from the software developers and the Centre for Enhancing Learning and Teaching (CELT), along with the promotion of online assessment through staff development, the use of this mode of assessment has increased very rapidly over the last three years (Figures 1 and 2) and extended to all faculties in a wide variety of disciplines. It is also being trialled at a divisional level by Student Services and the Library (Fry, 2006). As lecturers are discovering the benefits of online multiple choice assessment, so they are beginning to push the boundaries; the boundaries of online technology itself, as well as the boundaries of the appropriate educational application of the technology (Northcote, 2002). 


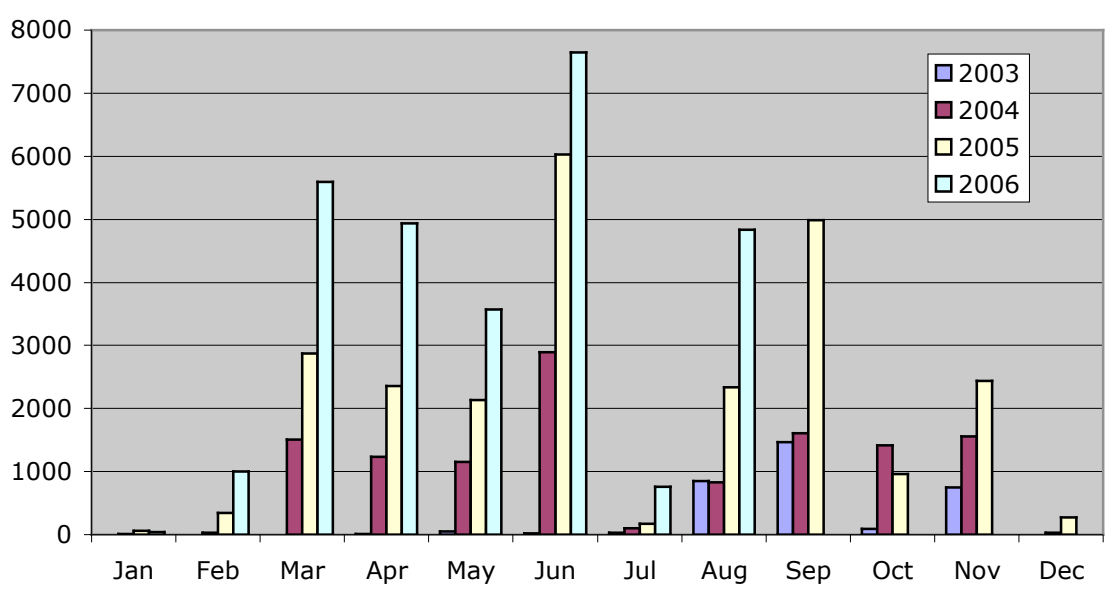

Figure 1: Growth in the number of individual OASIS test submissions. (Data includes multiple submissions by single users).

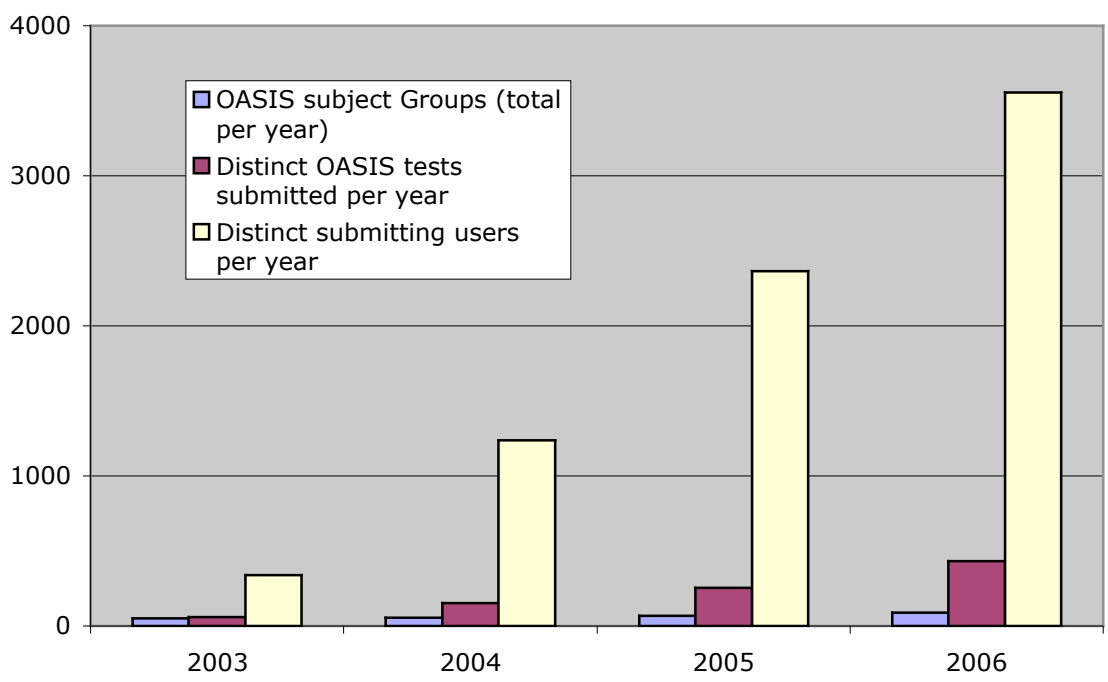

Figure 2: The usage of OASIS by comparison of subject groups, distinct tests submitted and distinct submitting users per year, 2003 to 2006.

The increased uptake of this particular application (Figures 1 and 2) has been due to the promotion by champions of this mode of assessment (Ely, 1999). These include academics and a nominated OASIS coordinator, who is an educational designer working closely with software developers, academics and other educational designers to promote the technology, 
provide professional development, and to ground online assessment in appropriate pedagogy. Academics research and share their experiences in online assessment through the Foundations of University Learning and Teaching program, and the Tertiary Teaching Colloquium and other forums (Wilkinson \& Dawson, 2000).

It is argued in this paper that the evolution of online assessment at CSU is more than just a simple linear exercise in software development. It encompasses and must necessarily integrate the simultaneous development of a variety of key support processes, professional development and associated research that collectively feed back into the improvement processes to produce a more sustainable and reliable online system (Buchan, 2004; Buchan, 2003).

Figure 3 provides a Venn diagram approach to illustrating the three major components of the integrated online system operating across a multicampus university, contributing to the effective delivery of online learning services.

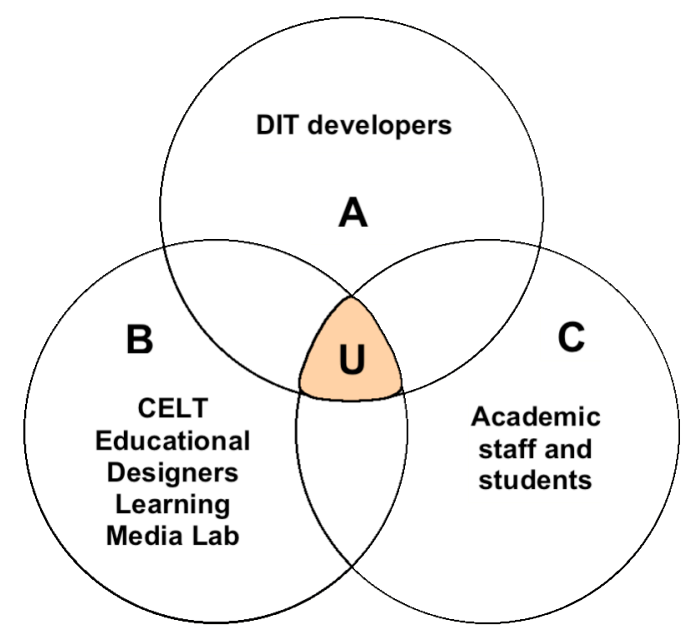

Figure 3: Major components of an integrated support system for online technologies
A: Division of Information Technology - providing and maintaining the IT services and support staff.
B: Centre for Enhancing in Learning and Teaching (CELT) - providing
C: School based academic staff - mediating student assessment through online systems such as OASIS 
Figure 3 identifies the critical intersection of components A, B and C, which must function optimally if large scale online assessment is to work. Our case study explores the consequences of a failure in the online system and is used to highlight the need for a fully integrated support system for online technologies. The case study follows the assessment experiences of a microeconomics subject offered in the School of Commerce at CSU. In 2006, during a major summative assessment event, a technical failure caused serious problems for the distance education cohort despite the careful planning of several years, including successful formative assessment tasks (Swann, 2004), the support from different divisions, and the preparation of the microeconomics students for the single major assessment event. In the ensuing reflection the question is posed: Is this 'A bridge too far' (Ryan, 1974) or a Bridge to the future?

The following extract from Michael Swann's report (2006) sets the background for the case study.

\section{Summative Assessment Test - 6th June 2006}

The (online assessment) OASIS Summative Test was set to commence at precisely $1.45 \mathrm{pm}$ on Tuesday 6th June AEST and to finish at precisely 3.00 pm. Overseas students from the UK (London) to Japan (Tokyo) had to set their clocks by NSW Tuesday 6th June AEST even though this meant sitting for their OASIS Test at for instance, $2.00 \mathrm{am}$ or $4.00 \mathrm{am}$ in their local time zones. Brave souls!

Somewhere just after $1.45 \mathrm{pm}$ as 171 [microeconomics]... students attempted to simultaneously log-on and access their Summative Test online... the OASIS Server at CSU-Albury campus sustained a critical overload failure... Students in droves reported by email ... a [series of problems]... after attempting to $\log$ on to the test:

The immediate consequences of the server failure were certainly dramatic:

1. My office phone went into meltdown

2. The Microeconomics Forum was deluged with around 300 postings from distressed DE students

3. The IT Help Desk received a tidal wave of calls from anxious, concerned and distressed DE students

4. Student Services were also deluged with calls from stressed and concerned DE students

5. The School of Commerce General Office phones rang continuously for an hour and half.

By any measure this was a very disappointing exercise... especially with the test counting for $20 \%$ of formal assessment in a B.Bus. foundation subject... The angst and sense of frustration across the ... DE student cohort was considerable. (Swann, 2006) 
This caused an immediate response from students - not only in NSW and across Australia but also from international students from London to Tokyo. Fortunately, the University's student support systems, from the IT Service Desk staff to the General Office staff in the School conducting the online test, responded swiftly and efficiently. The immediate response was to reschedule the online summative test for later in the same week and by dividing the students into two smaller sub-cohorts the test was run twice with complete success. In terms of our Venn diagram in Figure 3, the rescheduled test performed as planned because the critical DIT-CELTSchool interface worked efficiently to produce a successful online test - but only in its rescheduled second attempt.

The technical reason for the systems failure was traced to a temporary server failure which could not support the load placed on it by the large cohort access (Sefton, 2006). The uptake of this form of online assessment was far greater than anticipated, and therefore supported, by the particular server. Such a hardware failure is probably inexcusable today but this incident highlights the critical importance of communication within the integrated online support system illustrated in Figure 3, and the other components of support for online learning environments as proposed in our Bridge Support Framework below.

\section{A framework for integrated support - A bridge to the future}

In the first conversation after the 6 June 2006 systems failure, Michael Swann made the 'historic' comment, "It is disappointing: what we wanted was another D-Day success but what we got appears to be more like $a$ bridge too far". We had planned as well as possible, and factors largely beyond our immediate control were ultimately the undoing of the event on the day. Using student surveys (Table 1), investigations into the technical problems (Sefton, 2006) as well as detailed reports on these and other online assessment events (Buchan 2006; Buchan, 2005; Swann, 2006; Swann, 2004) we have been able to reflect on and use this situation and other instances of online assessment at CSU to improve our system and to build a bridge to the future.

Although the case study dwells on a particular incident and IT infrastructure failure, there is a myriad of other areas which can significantly affect the outcomes of an online assessment event. The authors introduce here their Bridge Support Framework for online learning. Developed within the context of online assessment, the framework has a more general application in mind and is intended for use in all areas of technology enhanced learning. The word 'framework', rather than 'model', has been carefully chosen because a framework per se is the structure one uses to support something and on which one builds the final product. A 
'model' provides an exact replica of something that others can copy, and in the strict, scientific, application of a model it would be used to predict outcomes and consequences of actions.

The initial framework was first defined in an internal discussion paper dated June 2006 (Buchan, 2006) in response to the case study events, and incorporating one of the author's years of experience in developing online assessment systems at CSU. A study of the literature has helped to refine the framework, and at the time of final submission of this paper, the authors have been able to review the success of the framework in the light of the (successful) Autumn 2007 offering of the microeconomics subject in our case study.

In comparison, the RIPPLES model for integrating instructional technology into higher education (Surry, Ensminger \& Haab, 2005; Surry, Ensminger \& Jones, 2003) addresses the barriers to integrating instructional technology into education. It has been described as a "...useful tool for analysing institutional innovations." (Benson \& Palaskas, 2006). We found significant similarities in our proposed initial framework with this model, in particular the academic focus. Surry, Ensminger and Jones (2003, p.2) note that their model "...is unique from most other technology integration models in that it includes facilitating factors that are specific to academic settings." The RIPPLES model provides an institutional focus and more depth to factors such as fiscal resources (budget) and infrastructure in its broadest institutional sense. Moreover, a gap in our original framework identified from the RIPPLES model is evaluation. Management of, and support for, online learning at an institutional level is necessarily interdivisional and requires a systems approach (Camp et al 2007; Uys, 2000). Thus the overarching communication is critical to the success of online learning. Ely (1990) in his seminal work cites eight conditions that appear to facilitate the implementation of technology innovations and reasons for adoption resulting in the diffusion of innovation. Our framework moves beyond implementation and focuses on support for online learning with its strong pedagogical foundation. It is intended for use at a variety of levels, from individual lecturer to institution.

While many institutions may appear to be well advanced in online learning, the demand for Web 2.0 technologies (Alexander, 2006) and the uptake of open source learning management systems (Wheeler, 2007) make the authors' Bridge Support Framework all the more important. The ACODE benchmarks for the use of technology in learning and teaching in universities (ACODE, 2006) confirm the importance of key issues such as support to promote continuous quality improvement in universities, through both staff development and student training as well as through institutional policy and IT infrastructure. 


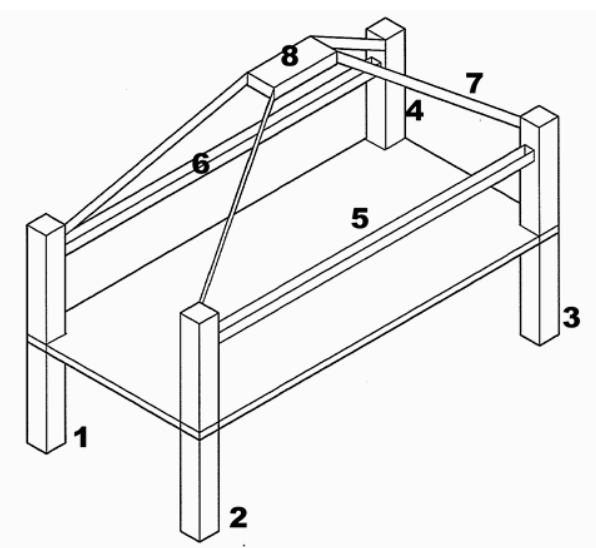

Figure 4: The Bridge Support Framework for Online Learning

1. IT infrastructure

2. Software/tools

5. Evaluation and research

3. Pedagogical (instructional) design 7. Communication

and academic research

4. IT support for end users

8. Institutional/administrative support and development of protocols and guidelines

The structure of the bridge support framework is now described in more detail. The graphic representation of the authors' four 'pillars' and two 'cross-beams' with a communication arch and boss at the apex of the communication arch of support is not intended to define a fixed prioritisation, but suggests that all components are of equal importance. There can be no weak link or the whole structure may fail. The four main pillars provide a foundation and the two cross-beams draw attention to the importance of certain links in the 'system' that ensure successful support for online learning. Individual institutions will have their own specific needs, strengths and weaknesses and our Bridge Support Framework provides a flexible blueprint to supporting online learning, more specifically, online assessment.

\section{IT infrastructure}

Camp et al (2007, p.26) note that "Managing IT infrastructure for higher education today is a balancing act. Institutions require high performance, reliability, scalability, agility, and a platform for innovation." The organisation's IT infrastructure, i.e. the servers and networks supporting individual online assessment tools, needs to be reliable and capable of supporting the projected use and loading of the system. Determination of this potential use requires effective communication between IT staff, developers and all end users. 


\section{Software}

The online assessment tool needs to be reliable. The software must be 'bug free', user friendly, and must meet the needs of the users (Wheeler, 2007). Wheeler also suggests that software needs to be flexible and adaptable to institutional needs (open source, in house), a need that must be balanced by institutional resourcing and costs. Professional development is required to ensure that users have a realistic expectation of what the online system or tool is capable of, are competent in its use (see below, 4. Support) and that appropriate risk management strategies are in place.

\section{Pedagogical (instructional) design and academic research}

Following a successful implementation of technology into a learning environment, the ongoing use of online technology to enhance learning needs to be grounded in pedagogy and research (Hardy \& Benson, 2002; Ely, 1999). Barone (2003) suggests that a collaborative association between instructional (educational) designer, specialist technology coordinator and academic is needed not only to enhance learning but to help to create a new learning environment. Our discussion here is confined to the use of online assessment.

Assessment is recognised as one of the key elements of the teaching and learning process (Nichols, 2003; McAlpine, 2002; James \& McInnis, 2001; Ramsden, 1992). Byrnes \& Ellis (2006) quote Kendle and Northcote to conclude that: "as such, assessment should be one of the first design considerations when preparing [a] ... course, and be seamlessly integrated into the course, not 'tacked on' as an afterthought.' Assessment design will draw on a number of the key elements of the Bridge Support Framework and is closely allied with research, planning, institutional policy and guidelines. Because of its centrality in the learning process, optimal assessment design should also take ongoing cognisance of student feedback and evaluation.

Planning typically might involve the academic, educational designer and specialist technology coordinator. Planning for the microeconomics assessment event is outlined below with more specific detail under the 'support' pillar of our framework. A model that is working well at CSU on a small scale is the designation of a specialist technology coordinator to provide support for pedagogical design, research and liaison with key stakeholders in online technologies (evidenced by the growth in uptake of online assessment from 2003 onwards, Figures 1 and 2). We perceive this role as pivotal in an integrated support system (Figure 3) for online technologies. A specialist technology coordinator can be described as an expert in the use of the technology and a 'champion' for the educational application of the technology. In this case study the (informal) role of 
OASIS coordinator is held by a CELT Learning Media Laboratory coordinator (educational designer). Similarly other technologies at CSU are supported informally by educational designers (academic developers) with interests and expertise in its use. As demonstrated through OASIS, this model has been successful in providing an active point of liaison between academic staff, IT developers and the administration (Figure 3) and will continue to be used in the expansion of CSU's online learning environment. Most importantly, it helps to ground the use of the educational technology firmly in the realm of learning and teaching, ensures that academic research is conducted, and that communication of this research reaches the right people for appropriate action.

Research

With the overabundance of different technologies today, users are in danger of being caught up in the pressure to use the technology according to the 'Mallory Principle' simply, 'because it is there' and without sufficient consideration for the quality of learning. It has been noted (Byrnes \& Ellis, 2006; Northcote, 2002) that, with the need to remain competitive, the move to online teaching and learning 'coupled with the importance of assessment as a critical component of the teaching and learning process, may in and of itself be sufficient justification for the use of online assessment' (Byrnes \& Ellis, 2006, p.105).

We have observed that those developing and implementing the online assessment technology are not usually the end users, and thus sound, situated research into the use of technology becomes essential to inform the development of the software itself (Buchan, 2006; James \& McInnis, 2001) as well as to inform the future acquisitions of online assessment tools in the new CSU online learning environment. Feedback from the users of CSU's online assessment technology has helped to position the technology for future developments and upgrades and to inform the acquisition of new systems to better serve the needs of the clients (Fry, 2006; Swann, 2006, Buchan \& Pitcher, 2005; Jenkins, 2005).

\section{IT support for end users: Staff and students}

In an educational environment, support for any online system or tool is important. In the case of online assessment the support becomes vital because, by its nature, the process of assessment is a critical part of a student's learning experience in a subject (Donnan, 2006). Any problems concerning the type, execution or mode of delivery of assessment can mean the difference between success and failure for a student, with potentially serious consequences for all parties concerned. The importance of support (or lack thereof) is also recognised as a barrier to the adoption of new technologies (Hagner, 2001; Ely, 1999). The evolution of support systems 
for online assessment at CSU has been gradual, and generally demand driven in response to perceived need, or as a direct reaction to problems associated with different situations.

Three different levels, or types of support that are required for end users of online technology are identified here (Buchan, 2006): training and professional development, troubleshooting and self help.

Live/real time training, professional development (workshops, one on one specialist help, etc.)

The delineation of responsibility for the training of users (staff and students) in using specific online technologies is a 'fuzzy' area in most institutions because of the nature of the type of support required. This ranges from technical competency (familiarity) with the software itself, to appropriate educational application in the learning environment (Figure 5). This delineation might be pedagogically separated according to Gagné and Glaser's (1987) five learned capabilities. Training deals largely with motor skills required to become competent in new technology, supported by intellectual and verbal information skills. Professional development might be seen to deal with the 'higher order' skills such as intellectual skills and cognitive (problem solving) strategies that empower users to apply the technology appropriately in their learning and teaching. There is no clear separation in training or professional development, but a continuum, which in itself is challenging for an organisation to manage where training and professional development are provided by different divisions. Depending on the structure of the organisation, responsibility for training can be placed on the (equivalent) division of information technology, a training or staff development division, or an academic development unit (educational designers, as in CSU's CELT). The regional, multi-campus nature of CSU presents particular challenges in providing adequate, real time training in the use of online technologies.

Troubleshooting - Help Desk oriented; immediate or delayed response (Help Desk sources appropriate support and, if needed, refers to specialists, available information, etc.)

Help Desk style troubleshooting for online tools comes from several sources at CSU: IT Services Help Desk, the CELT specialist technology coordinator, individual educational designers, and finally, academic staff for their own subjects.

The IT Services Help Desk is often the first point of call for students and staff using online assessment tools, because many problems with any online system manifest themselves as technical errors (even if it is user 'error', the users do not know this). The problems encountered by users of the in house software are very specific, which presents challenges for the 
Help Desk. Many of these problems are solved by pointing users to the relevant information on the web or direct contact with known 'experts' in the particular technology where needed. However, the scale of operations at CSU, with some 36,000 students of whom over half are distance education students, is challenging and we are still developing the necessary online resources and working towards achieving this level of inter-divisional communication. IT Customer Services is currently implementing the IT Information Library (ITIL) service management system which should potentially solve many of these problems (Director Customer Services personal communication, 8 July 2006).

Providing on call Help Desk support help for all online assessment events on the scale now being used at CSU (Figure 1) is, however, unrealistic and undesirable. An online system should be robust enough to support the usage it gets. Furthermore, prior training and professional development for users, as well as planning the use of technology for learning and teaching should minimise major demands on the Help Desk services.

Self-help - web information and print resources, these can help cover the functions of training/professional development and troubleshooting if set up correctly

Self help support for online assessment tasks comes from a variety of different areas and should be tailored to individual learning needs and styles (Gagné \& Glaser, 1987) and the specific cohort, i.e. distance education or on campus students (Hicks, Reid \& George, 1999). Support includes general information on the application made available on the web (help documents, how to guides, etc.); pre-prepared subject specific information provided in the Subject Outline; and familiarisation or practice tests.

Although there was no coordinated system for the development of web based guidelines for the various in house software applications, the model of having a single specialist technology coordinator for individual applications, such as OASIS, is helping to streamline the development of 'self help' resources. This is also being expedited in the implementation of the CSU online learning environment, CSU Interact, through a coordinated, interdivisional approach to developing training and support material.

In summary, direct support for staff users of online assessment tools at CSU comes largely from CELT. There is minimal support available for student users of OASIS except for information on the Student Services website (CELT initiative) and any support provided by subject lecturers. The OASIS coordinator deals directly with staff and, occasionally, students on an individual needs basis. 


\section{Evaluation and research}

Surry, Ensminger \& Jones (2003) describe evaluation as the need for continual assessment of the technology. They identified four areas of evaluation to be considered by administrators in the integration of technology into learning environments. Keeping the focus on learning, and adapting these for our support framework we identify three key areas in online technology that need to be evaluated to facilitate continual improvement in learning outcomes within a technology enhanced learning environment. Firstly, evaluation of technology in relation to learning goals; secondly, evaluation of the technology including an ongoing assessment of technology alternatives and, finally, a cost/benefit evaluation to determine the return on investment for any technology expenditure.

The cost/benefit evaluation is perhaps controversial in an academic environment, but in the highly competitive contemporary educational environment where the users (staff and students) are effectively the 'clients' of those providing the technology, consideration of dollar benefits does become important. However, the perceived benefit of the technology will not equate simply to numbers of users, but quality, achievement of learning outcomes, innovation and other factors can be incorporated into the calculations of benefit.

\section{Budget}

Funding has been identified as a top ten IT issue (Camp et al., 2007) for the past eight years. No institution can afford the ad hoc acquisition of individual applications without adequate financial planning for maintenance and future developments. Budget considerations in managing the online learning environment operate at a number of levels: organisational, divisional, faculty, school and individual. Budget considerations are also dependent on the (perceived) responsibilities each area has for sustaining specific aspects of the online learning environment (Jackson, 2007). In 2006 the authors identified a number of budget related shortfalls in planning that have impacted on online assessment including lack of training for students in use of software (no division had staff designated to this task), IT infrastructure limitations (this has been addressed in a recent server upgrade) and a lack of coordinated development of self help support materials.

\section{Communication}

Working with innovative, exciting and sophisticated new online technologies not only expands the frontiers of the educational services offered by the University in this age of web based learning, but also reinforces our acute awareness of and dependence on the central role of team effort in the emerging e-learning environment. (Swann, 2004) 
The development of reliable online learning systems is acknowledged to be a team effort (Kerka \& Wonnacott, 2006; Uys, 2000). Inter-divisional, intradivisional and staff-student communication have all been important in the evolution of online assessment at CSU. In the Venn diagram of Figure 3, the critical intersection of the three components for successful online assessment is where communication is paramount (Hagner, 2001). The RIPPLES model identifies people as a key element. However, we use 'Communication' purposefully, where the important human interactions become implicit. Our bridge framework has attempted to emphasise this aspect by making communication a component which connects and informs all the other components of the bridge.

\section{Institutional and administrative support and development of policy, protocols and guidelines}

There is a need for organisational policies and procedures to be developed for new technologies (Surry, Ensminger \& Jones, 2003). The issues associated with the administrative and institutional support of online assessment include policy development (institutional to school level), and equity of access and accessibility issues (Sim, Holifield \& Brown, 2004). For administrative purposes, in 2005 CSU mandated Internet access for all students in its admission requirements (University Handbook 2005 Section 5.1), and minimum IT access requirements are currently (June 2007) under review. The University now "...assumes that all on campus and distance education students at CSU will have ongoing access to an internet connected computer capable of communicating with CSU online systems" (Senate, 2007).

At CSU a coordinated approach to the development of university assessment and admission policy, regulations, protocols and guidelines and recommendations for IT access is essential, as we move to a more extensive online learning environment with the introduction of both an LMS and a digital object management system. Clearly no single policy concerning online access and use of technology in assessment can cover all uses of all applications without limiting innovation and use of the technology. A theoretical 'model' of how policy, protocols and guidelines in relation to IT access can be developed and introduced at appropriate institutional levels is shown in Figure 5.

As the use of online assessment has increased, it has become clear that academic staff are using the technology in a variety of innovative ways, but not all are necessarily educationally appropriate, and more recently issues associated with equity and accessibility have emerged for discussion. In determining the appropriate use of this mode of online assessment, our case study has been able to draw on past experiences and the consequent 
development by CELT of 'protocols and guidelines' in response to a perceived need. However, as is the case in many institutions (W. Jackson, UNSW@ADFA, personal communication, September 2006; Donnan, 2006), the development of overarching policy, protocols and guidelines and institutional strategies (Sim, Holifield \& Brown, 2004) to support new technologies is lagging behind the technology itself.

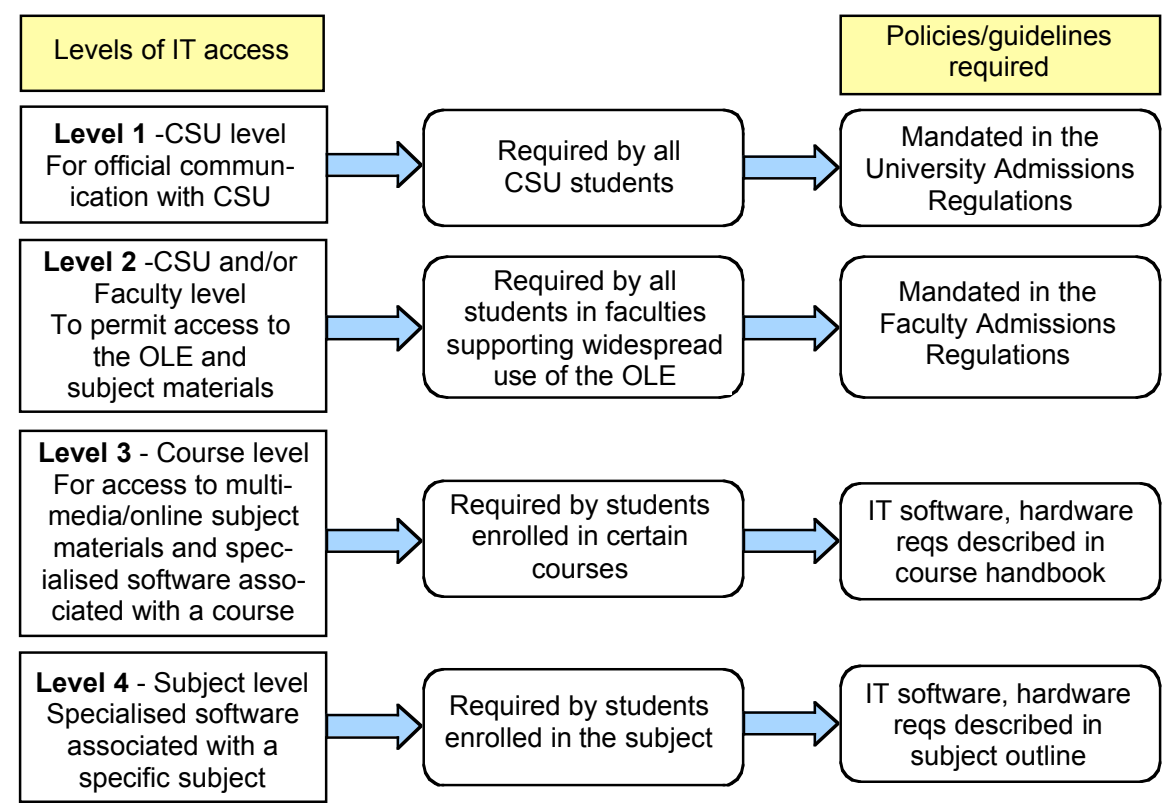

Figure 5: A model of a levels of IT access approach to the development of policy, protocols and guidelines

Historically, online assessment through OASIS began as a small local, interdivisional pilot project. The rapidly increasing use of this form of assessment has meant that online assessment outgrew its 'pilot mode' before the support processes and product development could be fully mainstreamed with adequate funding and institutional recognition. The move from pilot to mainstream and associated support processes is a potential weak link in the success and scalability of any online tool or system and highlights the need for institutions to have a coordinated approach to managing their online learning environment.

\section{Microeconomics case study}

Why online summative assessment in Autumn semester 2006? In microeconomics, students are exposed to multiple choice questions in both 
their session assignments and in the end of semester final exam. The nature of microeconomics as a subject with its regular use of mathematical concepts, tables of data, diagrams and frequent technical terms lends itself to at least partial assessment by use of multiple choice questions (Judge, 1999). Well constructed multiple choice questions can be effective in testing everything from simple cognitive skills related to a memorised economics vocabulary and application of technical terms through to data generated problems requiring analytical and well defined problem solving skills to be demonstrated by the student (Clarke et al, 2004; McKenna \& Bull, 2000).

The transition from online formative assessment modes to a first attempt at summative assessment in a large size distance education student cohort (around 200) evolved over the years 2003 to 2006, in tandem with the evolving in house online assessment software. After experimenting and working with formative assessment tests between 2003 and 2005, it was felt that the move to large cohort summative assessment could be trialled in the Autumn semester of 2006. The costs involved were minimal in terms of test preparation and informing students through subject outlines (hard copy) and subject forum postings. The benefits to academic staff and students were significant and divided into two broad categories.

a. The pedagogical benefits from online assessment included both student focused gains in the learning experience and lecturer focused gains in teaching methodology. Formative assessment, through a series of four multiple choice question tests run in conjunction with the students' subject modules in microeconomics, had received generally positive feedback from student surveys, as indicated by the results shown in Table 1. Distance education students gained an opportunity for immediate learning feedback on their test performance (Benson, 2003; Kerka \& Wonacott, 2000; Northcote, 2002), supplemented by additional test solution sets posted on the subject forum immediately after the close of the summative test. With assignment turn round time eliminated from the semester schedule, the timing of the summative test could be optimally placed to assess the maximum number of subject topics with online feedback prior to the final exam.

b. The administrative benefits included time saving involved in administrating large student cohort assignments, time savings in administering academic markers by the School, and the avoidance of clerical error by the substitution of computer generated marking and spreadsheeting functions.

The lecturer focused gains in teaching methodology concentrate on an application of the model of constructive alignment established by John Biggs in his seminal work Teaching for Quality Learning at University (2005). Essentially, students complete the online microeconomics tests consisting 
of multiple choice questions, specifically aligned to learning objectives embedded in the set of subject modules. The online assessment software then permits a formal statistical analysis of large cohort performance, identifying through quantitative indicators how well aligned the learning objectives are with the specific test questions set to assess student understanding of each particular learning objective.

Through use of a longitudinal study commencing in Autumn 2006 and going through to Autumn 2007 and beyond, it has been possible to use the online assessment tool to better align the student learning objectives with the assessment tasks themselves, i.e. the multiple choice test. The lecturer can identify areas of poor to weak student performance in tests, suggesting the need to improve how well the learning objectives, assessment modes and subject modules align in order to optimise the learning experience for the students in future semesters.

Table 1: Student perceptions of the value of online multiple choice assessment in enhancing learning.

\begin{tabular}{|c|c|c|c|c|c|}
\hline \multirow{2}{*}{ Question } & \multicolumn{5}{|c|}{$\begin{array}{c}\text { Numbers of respondents } \\
\text { Total survey group (Micro) }\end{array}$} \\
\hline & $\begin{array}{c}\text { Strongly } \\
\text { agree }\end{array}$ & Agree & Unsure & $\begin{array}{l}\text { Dis- } \\
\text { agree }\end{array}$ & $\begin{array}{l}\text { Strongly } \\
\text { disagree }\end{array}$ \\
\hline $\begin{array}{l}\text { The use of multiple choice questions } \\
\text { per se (i.e. both print or online modes) } \\
\text { is an appropriate way of conducting } \\
\text { assessment in this subject. }\end{array}$ & $52(8)$ & 61 (19) & $6(1)$ & $4(2)$ & $0(0)$ \\
\hline $\begin{array}{l}\text { I found that the online multiple choice } \\
\text { assessment exercises available as } \\
\text { formative assessment in my subject } \\
\text { helped me achieve the subject } \\
\text { objectives. }\end{array}$ & $25(4)$ & $59(17)$ & $17(6)$ & $3(3)$ & $19(0)$ \\
\hline $\begin{array}{l}\text { I found that the online multiple choice } \\
\text { assessment exercises available as } \\
\text { formative assessment in my subject were } \\
\text { appropriately designed for this level of } \\
\text { study. }\end{array}$ & $28(4)$ & $56(16)$ & $17(8)$ & $2(2)$ & $20(0)$ \\
\hline $\begin{array}{l}\text { The use of online multiple choice } \\
\text { assessment as a summative assessment } \\
\text { tool (i.e. counts towards your final } \\
\text { grade) was an appropriate way of } \\
\text { conducting assessment for this subject. }\end{array}$ & $33(5)$ & $39(13)$ & $11(5)$ & $9(9)$ & $25(1)$ \\
\hline
\end{tabular}

At the end of the Autumn (first semester) session in 2006, students from a number of different subjects that used online multiple choice assessment in 
some form were surveyed. It is beyond the scope of this paper to report on this research, although the provisional results of the study (Table 1) are encouraging in support of this form of assessment for both formative and summative purposes.

Aspects of the Bridge Support Framework are discussed below with reference to the case study.

Institutional and administrative support

The guidelines developed for using OASIS in assessment recommend that:

OASIS is best used as a formative assessment tool .... There are significant issues concerning plagiarism and security concerns associated with online submission of tests. Staff also need to be mindful of equity in student access to online facilities. However, with careful planning OASIS can be used to support summative assessment tasks. (Centre for Enhancing Learning and Teaching, 2005)

Faculty of Business policy requires that all students will have access to a computer for the primary purpose of assignment writing. The use of online assessment has been in place in microeconomics since 2003 and as part of summative assessment since 2006. Students are advised from the commencement of each Autumn semester that online assessment is a part of the subject. To date we have had no experience of any distance education student claiming disadvantage on equity grounds due to lack of online access. Alternative assessment arrangements are put in place for individual students on request.

Pedagogical (instructional) design, planning and research

Supported by a Scholarship in Teaching fund grant we are hoping to move beyond the practicalities of online assessment, with the aims of our study being 'to measure the effectiveness of online multiple choice assessment as a teaching and learning tool and to develop a model of constructive alignment between learning outcomes and multiple choice questions' (Buchan, Wilkinson \& Swann, 2006; Biggs, 2005). It is beyond the scope of this paper to report fully on this study although some of the preliminary findings have been included (Table 1 and student feedback).

Online assessment design fits within a pre-existing assessment framework. In the first year microeconomics subject the online tests represent only one component of the total subject assessment. Students are expected to provide written assignment work during the semester as well as to sit a three hour closed book, invigilated final examination in the subject. The final examination receives a minimum of $50 \%$ weighting and must be passed as one of the conditions governing the award of subject grades at CSU. The microeconomics online tests are designed with a range of 
questions which test student knowledge of technical concepts as well as longer, more data and/or graphics based questions which test student problem solving ability in the subject. Not only do students receive immediate feedback on submission of their tests, but the subject forum is also used to post solution sets for students to assist them analyse which was the correct answer and why a particular answer was correct in terms of microeconomic models and their analysis.

Finally, this online assessment mode provides a technical solution that permits the lecturer to explore ways in which student learning outcomes can be evaluated, revised and improved over time. For large student cohorts, it is only the comparatively recent advent of online assessment technology that makes such pedagogical research tasks feasible with limited resources in both time and funds.

\section{Budget}

On a practical level, one of the more tangible benefits of the move to online summative assessment modes has been the budget savings at the School (and ultimately the Faculty) level. For large student cohorts, assignment marking is a labour intensive, time consuming and regular budget item for the School. In 2006, by moving from a written second assignment to a one hour online summative test with computer generated student results, several thousands of dollars were saved from the School budget. It is suggested that these funds can then be allocated to the development of additional and upgraded online facilities at CSU or reallocated to other more urgent purposes within the organisation. The funds saved from School budgets by the increasing adoption of online tests across the University can also be viewed as a potential model of transfer pricing within the University - sensitising the central administration to the growing demand for online services across Schools and campuses and identifying a flow of funds from School based budgets that would determine the 'transfer price' of online services as provided by DIT to Faculties/Schools within the organisation.

At a University level, the final recommendations of a working party are now informing the expansion of the University's Online Learning Environment (OLE) (Virtual Learning Environment Working party, 2005; ILSC, 2004) through a specially funded OLE program. This has led to the selection of Sakai as an open source learning management system (Tulloch, 2005). This strategic approach to the development of the VLE makes use of available funding to position the University strongly in its focus on flexible learning with the university wide implementation of Sakai as part of CSU's new OLE, CSU Interact, in 2008. Funding has equated not only to the actual software, but also to new support positions in CELT and the Learning Materials Centre (LMC) for implementation of CSU Interact. 


\section{Communication}

The Bridge Support Framework identifies communication as an essential part in the provision of online learning systems. A weak point identified through our case study has, however, been a lack of aspects of interdivisional communication and inadequate procedures to ensure the robustness of the technology for current usage (Sefton, 2006). Communication is particularly important in real time events such as the microeconomics summative assessment event. We argue that the microeconomics case study is an exemplar of successful communication in many aspects and has led to the development of a number of processes and procedures that have been adopted throughout the University (guidelines for Subject Outlines, feedback to the developers for upgrades to software, protocols for the appropriate implementation of online assessment in a subject). Improvements that have already occurred as a consequence of the initial summative test experience is that DIT is now being advised on a semester by semester basis when School based subject coordinators are scheduling large cohort summative tests and improvements in userdeveloper communication has seen upgrades to both software and hardware.

\section{IT infrastructure}

Although the CSU system has been used extensively for a variety of large cohort assessment tasks in other subjects (Figure 2), load testing of the system under the particular circumstances had not been done prior to the 6 June 2006 microeconomics summative test (Sefton, 2006), although technical assurances were that the system could handle the load. We have instituted improved communication between the developers, IT infrastructure maintenance staff, and the end users of the technology (academic staff and educational designers) to ensure the relevant IT staff understand the potential use of the online systems, so that appropriate tests and changes can be made. Similarly, through professional development, end users are made aware of the limitations of the system, and their own individual responsibilities in using technology for live, online assessment events, so that they do not use it for purposes which the IT infrastructure cannot realistically support and which may result in a systems failure at a critical juncture.

\section{IT support for end users}

Live/real time training, professional development

In the case of microeconomics the lecturer received initial exposure to online assessment software training through regular interaction with both School based (the Educational Designer) and relevant CELT staff. As with most software, much expertise had to be acquired through 'learning by doing', by working with the software through a few semesters of purely formative assessment tests. 
A noticeable weak point in our 'bridge' is that there is generally no formal training available for student users of online learning technologies. This puts the responsibility for familiarising the students with the online assessment system on the lecturers. Initial feedback from students in our study confirms the current inadequacy of student support. This weak point is being addressed in CSU's implementation of its new learning management system, through a more holistic approach to IT support, development of resources for students by Student Services, and an integrated professional development plan (Gill \& Hardham, 2007).

Troubleshooting - Help Desk oriented

Following the de-briefing on our microeconomics case study, it was recommended that staff familiar with the application (DIT staff and/or the OASIS coordinator) be available for on call support for major summative assessment tasks in monitoring the IT infrastructure, and the IT Service Desk be notified of major assessment events. The subsequent introduction of this coordinated approach has already seen success.

In the microeconomics subject, individual support is available to students through email and phone calls made directly to the lecturer. This works reasonably well when only a few students seek help at random times and in relation to minor problems associated with formative tests. But the support system is not designed to cope with the level of student demand for help as occurred on our 6 June summative test. On reflection, under such one off circumstances - the Subject Forum provides the best means of group response - more effective and potentially more reassuring than individual phone calls or emails.

The Subject Forum (discussion board) was also enlisted as a useful ongoing means of identifying OASIS issues and addressing ad hoc questions and problems that emerged. The Forum proved to be a valuable adjunct to the Subject Outline, providing students with ongoing support while they familiarised themselves with the new technology. Most of the issues identified by students related to online access and the avoidance of routine navigational errors in moving through the online test. Through Forum postings students became adept at helping each other with minor software navigational problems. Email also proved a useful tool for dealing with individual student queries concerning access and navigation.

Student Self Help

In the first year microeconomics subject, student self help was largely provided by a variety of means as outlined below.

- Practice tests - Intense use was made of formative tests prior to the introduction of a summative test. Typically, students attempted four 
formative tests per semester in line with completing their four modules in the subject.

- 'Print' resources - The Subject Outline was updated to include a new section on introducing the OASIS online software and outlining the benefits of moving to online assessment. Students were able to access the online assessment tasks through a hyperlink in their online subject outline.

- Web resources - Students and staff have access to a variety of web based resources; the Student Guide to OASIS available on the CSU Student Services website, the staff guidelines on the OASIS and the online Help guide available with the OASIS application itself.

\section{Conclusion}

There are certain inherent 'frailties' in online technology that imply the presence of a certain amount of 'risk' associated with the use of the technology (Northcote 2002). These frailties are not limited to the actual technology (hardware and software concerns), but also to the administrators and organisational (cross-divisional) support of the technology, users of the technology, the dependence on their competence and familiarity with the technology (i.e. for lecturers this equates to setting up appropriately designed online assessment tasks, for students it is accessing and completing the tasks) that is also critical to the successful use of the technology.

Initial indications and student reaction during the case study event were that using online multiple choice assessment for summative assessment may be a 'bridge too far'. This is, at least partially, supported by the preliminary results of our research (Table 1) in which some $23 \%$ of microeconomics students (and $25 \%$ of our total survey group) disagreed with the use of online multiple choice assessment as appropriate for summative assessment purposes. While we would like to explain away this feedback as a 'once off' unfortunate experience with technology, the realities of the operations of online systems and their inherent 'instabilities' will remain and need to be factored into any consideration of the use of online assessment technologies. We cannot dismiss the very personal feedback from students.

The technical difficulties relating to our online summative assessment... created a lot of unnecessary stress and anxiety for myself and many students, who organised their lives around being available for this test. We had 4 month's notice for this online test, and due to it not being available on the day, we had 24 hours' notice to complete it again on another day, around working full-time etc with no preparation. ... For formative assessment, 
OASIS was excellent. There is potential for this technology to be an excellent summative assessment tool, as long as it works! (microeconomics student A, Research survey feedback, 6 June 2006)

I found having access to the on-line OASIS formative (if that's the right word - the non-assessable ones!) tests invaluable as a self-test resource during the semester, and a good way for a new student like myself to get a feel for the way that questions are phrased in this subject. I'm actually looking forward to doing other subjects that may have the same capability (microeconomics student B, Research survey feedback, 10 June 2006).

In this paper we have reflected on our experiences with online assessment over a number of years, considered student feedback from our research, and examined the literature to develop a bridge to the future, a framework for the integrated support of online learning; the Bridge Support Framework for online learning. It is hoped that this framework, together with the developing model of integrated support for online systems at CSU (Figure 3) and our ongoing research will go some way towards guiding institutions in developing robust and reliable online learning, and specifically online assessment, systems. CSU faces challenging and exciting online developments as it moves towards the implementation of its new, open source, learning management system from 2007 onwards. The principles developed in this paper will hopefully play a constructive part in the immediate future of CSU Interact, the University's new online learning environment.

\section{Acknowledgements}

We are indebted to all academics pursuing innovative ways of teaching their subjects: to our colleague Dr Jenny Wilkinson for her commitment to our online assessment research, to Lincoln Gill for his sound educational design and support of online technologies, and to those DIT developers and staff who took on the challenge of programming for online assessment and who continue to support our research, particularly Matt Morton-Allen, Vicki Pitcher and their team.

\section{References}

ACODE (2006). Benchmarks for the use of technology in learning and teaching in Universities Australasian Council on Open, Distance and E-learning. http: / / www.acode.edu.au/ projects / acodebenchmarksfullfinalnov06.pdf

Alexander, B. (2006). Web 2.0: A new wave of innovation for teaching and learning? Educause Review, 41(2), 32-44. http:/ / www.educause.edu/ir/library/pdf/erm0621.pdf

Barone, C. A. (2003). The changing landscape and the new academy. Educause Review, 40(5), 41-47. http: / / www.educause.edu/ir/library/pdf/erm0353.pdf 
Benson, A. D. (2003). Assessing student learning in online environments. New Directions for Adult and Continuing Education, 23(100), 67-78.

Benson, R. \& Palaskas, T. (2006). Introducing a new learning management system: An institutional case study. Australasian Journal of Educational Technology, 22(4), 548-567. http:/ / www.ascilite.org.au/ajet/ajet22/benson.html

Biggs, J. (2005). Teaching for quality learning at university, 2nd edition, Society for Research into Higher Education \& Open University Press, UK.

Buchan, J. (2006). Online assessment at Charles Sturt University: A bridge too far? An internal discussion paper on the use of OASIS and online assessment for summative purposes. June 2006. Centre for Enhancing Learning and Teaching. Charles Sturt University.

Buchan, J. Wilkinson, J. \& Swann, M. (2006). Education driving technology: An investigation into the effectiveness of online multiple choice assessment as a teaching and learning tool. Scholarship in Teaching Fund application. Charles Sturt University.

Buchan, J. \& Pitcher, V. (2005). Online assessment at Charles Sturt University: Education driving technology. Poster paper presented at CSU Learning and Teaching Conference, Bathurst, September 2005.

Buchan, J. (2004). Report detailing suggestions for improvements to the current OASIS system, and a 'wish list' for functionality of future online testing tools at CSU. 4 November 2004. Centre for Enhancing Learning and Teaching, Learning Media Laboratory. Charles Sturt University.

Buchan, J. and Buchan, A. (2003). Lessons from nature: Developing an adaptive management model for sustaining quality learning environments. Sustaining Quality Learning Environments. Proceeding 16th ODLAA Biennial Forum. Open and Distance Learning Association of Australia. http: / / odlaa.une.edu.au/publications/2003Proceedings/pdfs/buchan.pdf

Byrnes, R. \& Ellis, A. (2006). The prevalence and characteristics of online assessment in Australian universities. Australasian Journal of Educational Technology, 22(1), 104-125. http: / / www.ascilite.org.au/ajet/ajet22/byrnes.html

Camp, J. S., Deblois, P. B. \& the 2007 Educause Current Issues Committee (2007). Top 10 IT Issues 2007. Educause Review, 42(3), 12-32. [verified 22 Jul 2007] http:/ / www.educause.edu/ir/library/pdf/erm0730.pdf

Centre for Enhancing Learning and Teaching. (2005). Guidelines and protocols for using OASIS in assessment. Centre for Enhancing Learning and Teaching, Learning Media Laboratory. [viewed 19 Sep 2006] http: / / www.csu.edu.au/division/landt/ resources / oasis.htm\#protocols

Clarke, S., Lindsay, K., McKenna, C. \& New, S. (2004). Inquire: A case study in evaluating the potential of online MCQ tests in a discursive subject. ALT-J, 12(3), 249-260.

Donnan, P. (2006). Supporting e-assessment. ODLAA Times, 14(2), 7-9. Open and Distance Learning Association of Australia. 
Ely, D.P. (1999). New perspectives on the implementation of educational technology innovations. Evaluative Report. ERIC. http:/ / www.eric.ed.gov/ ERICDocs/data/ericdocs2sql/content_storage_01/0000019b/80/17/5c/c0.pdf

Ely, D. (1990). Conditions that facilitate the implementation of educational technology innovations. Journal of Research on Computing in Education, 23(2), 298-305.

Fry, G. (2006). Library OASIS tutorial trial: Evaluation. Internal memorandum. Greg Fry, Manager, Client \& Information Services, Albury Wodonga Campus, Charles Sturt University.

Gagné, R. M. \& Glaser, R. (1987). Foundations in learning research. In Instructional technology: Foundations. Lawrence Erlbaum Associates. New Jersey. pp.49-83.

Gill, L. \& Hardham, G. (2007). CSU Interact. Professional Development plan. Version 1.5. 31 May 2007. Centre for Enhancing Learning and Teaching. Charles Sturt University.

Hardy, L. \& Benson, R. (2002). Through the looking glass: Roles, relationships and reflective practice to improve the use of educational technology. In S. McNamara \& E. Stacey (Eds.), Untangling the web: Establishing learning links. Proceedings ASET Conference 2002. Melbourne, 7-10 July. http: / / www.ascilite.org.au/aset-archives/ confs / 2002/hardy.html

Hagner, H. R. (2001). Interesting practices and best systems in faculty engagement and support. Final report. NLII White paper. University of Hartford. http: / / www.educause.edu/ir/library/pdf/NLI0017.pdf

Hicks, M., Reid, I. C. \& George, R. (1999). Designing responsive online learning environments: Approaches to supporting students. Proceedings AARE Conference. http:/ / www.aare.edu.au/99pap/hic99172.htm

ILSC (2004). Information and Learning Systems Committee. Action sheet. 27 July 2004. Charles Sturt University.

Jackson, G. A. (2007). Compartments, customers or convergence? Evolving challenges to IT progress. Educause Review, 42(3), 35-49. http: / / www.educause.edu/apps/er/erm07/erm0731.asp

James, R. \& McInnis, C. (2001). Strategically re-positioning student assessment. A discussion paper on the assessment of student learning in universities. University of Melbourne, Centre for the Study of Higher Education.

Jenkins, S. (2005). Survey of use of OASIS in human resources second year subject. (Unpublished). School of Commerce. Charles Sturt University.

Judge, G. (1999). The production and use of on-line Web quizzes for economics. Computers in Higher Education Economics Review, 13(1). [verified 22 Jul 2007] http:/ / www.economicsnetwork.ac.uk/cheer/ch13_1/ch13_1p21.htm

Kerka, S. \& Wonnacott, M. E. (2000). Assessing learners online. Practitioner file. Office of Educational Research and Development. Washington DC. [verified $22 \mathrm{Jul}$ 2007] http: / / www.cete.org/acve/docs/pfile03.htm

McAlpine, M. (2002). Principles of assessment. Bluepaper Number 1. February 2002. Robert Clark Centre for Technological Education. University of Glasgow. CAA Centre TLTP Project. Published by The CAA Centre. 
McKenna, C. \& Bull., J. (2000). Designing objective test questions: An introductory workshop. [viewed 1 May 2003, verified 23 Jul 2007] http:/ / www.caacentre.ac.uk/dldocs/otghdout.pdf

Nichols, M. (2003). Using eLearning tools for assessment purposes. 16th ODLAA Biennial Forum Conference Proceedings Sustaining Quality Learning Environments. Open and Distance Learning Association of Australia. [verified 23 Jul 2007] http: / / odlaa.une.edu.au/publications / 2003Proceedings / pdfs / nichols.pdf

Northcote, M. (2002). Online assessment: Friend or foe? Colloquium. British Journal of Educational Technology. 33(5), 623-625.

Ramsden, P. (1992). Learning to teach in higher education. Routledge, London.

Ryan, C. (1974). A bridge too far. Hamish Hamilton, London.

Sefton, P. (2006). Report on the failure of the OASIS application. Division of Information Technology, Customer Services. Internal report July 2006. Charles Sturt University.

Senate (2007). Charles Sturt University Senate decision. Reported in M. Tulloch. Centre for Enhancing Learning and Teaching, Director's report June 2007. Internal document.

Sim, G., Holifield, P. \& Brown, M. (2004). Implementation of computer assisted assessment: lessons from the literature. ALT-J, Research in Learning Technology. 12(3), 215-229.

Sivapalan, S. \& Cregan, P. (2005). Value of online resources for learning by distance education. CAL-laborate. Uniserve Science, University of Sydney. pp.23-27. [verified 23 Jul 2007] http:/ / science.uniserve.edu.au/pubs/callab/vol14/cal14_sivapalan.pdf

Surry, D. W., Ensminger, D. C. \& Haab, M. (2005). A model for integrating instructional technology into higher education. British Journal of Educational Technology, 36(2), 327-329.

Surry, D.W., Ensminger, D. C. \& Jones, M. (2003). A model for integrating instructional technology into higher education. [viewed 30 May 2007, verified 23 Jul 2007] http: / / www.iphase.org/ papers / RIPPLES.rtf

Swann, M. (2004). Online assessment using OASIS: Strategies for a flexible learning environment: the recent experience from the economics discipline. December 2004. School of Commerce. Faculty of Commerce. Charles Sturt University.

Swann, M. (2006). Report on OASIS performance: Some reflections on an evolving technology. July 2006. Internal report. School of Commerce. Charles Sturt University.

Tulloch, M. (2005). (Internal memorandum). Memo To: Deputy Vice-Chancellor (Academic). Report on Current VLE Projects for Learning \& Teaching Plan 20072011. Marian Tulloch. Director of CELT.

University Handbook (2005). Charles Sturt University Academic Manual. http: / / www.csu.edu.au/acad_sec/manuals/contm.htm

Uys, P. M. (2000). Towards the virtual class: Key management issues in tertiary education. Unpublished PhD thesis, Victoria University of Wellington, New Zealand. [verified 23 Jul 2007] http:// www.globe-online.com/philip.uys/phdthesis 
Virtual Learning Environment Working Party (2005). Towards the enhancement of the CSU Virtual Learning Environment. Report to the ILSC of VLE working Party. September 2005. Charles Sturt University.

Wheeler, B. (2007). Open source 2010: Reflections on 2007. Educause Review, 42(1). 48-67. http: / / www.educause.edu/ir/library/pdf/erm0712.pdf

Wilkinson, J. \& Dawson, S. (2000). Use of OASIS, a self assessment tool, to enhance student learning Presentation at Centre for Enhancing Learning and Teaching, Charles Sturt University Forum.

Janet F. Buchan (author for correspondence)

Educational Designer/Learning Media Laboratory Coordinator

Centre for Enhancing Learning and Teaching

Charles Sturt University, PO Box 789, Albury NSW 2640, Australia

Email: jbuchan@csu.edu.au

Michael Swann, Lecturer in Economics

School of Commerce, Faculty of Business

Charles Sturt University

PO Box 588, Wagga Wagga NSW 2650, Australia

Email: mswann@csu.edu.au 